\title{
Microcontroller Training Kit Design Compatible with Drawings of the ISIS Simulation Program
}

\author{
H. Apaydin, N. Fusun Oyman Serteller
}

\begin{abstract}
Microcontrollers are inside all areas of industry today. They are being used in many electronic circuit designs, ranging from very simple systems to highly complex systems. For that reason, microcontrollers have a great importance in the electronics sector. Microcontrollers are especially important in terms of students enrolled in engineering departments in the fields of computers, electrical engineering, electronics, and mechatronics. Experimental sets and simulation programs are used in the learning and teaching of microcontrollers in real-world simulations. In this study, a 16F877 microcontroller training set, designed for use in microcontroller courses, was used. The designed training kit allows experimentation with the 16F877 microcontroller circuits as a subprogram of the Proteus program of Lab center Electronics, which is electronic circuit drawing in Proteus ISIS (Intelligent Schematic Input System) simulation software tested in a real environment. The microcontroller basic hardware connections and the application circuits on the training kit were implemented as modules similar to the ISIS program drawings. Transition from the simulation environment to the real-life environment can be done easily by using these modules, and the information learned in this way becomes concrete.
\end{abstract}

Keywords- Electric-electronic circuit drawing, ISIS program, Microcontroller, Training kit.

\section{INTRODUCTION}

$\mathrm{A}$ dvancements in today's semiconductor technology have changed the way industrial fabrication and processcontrol problems are resolved. The microcontroller makes it

H. Apaydın is a Lecturer in the Department of Biomedical Device Technology Program, Kütahya Dumlupınar University, Turkey (e-mail: hasbi.apaydin@dpu.edu.tr)

N. Fusun Oyman Serteller is a Professor in the Department of Electrical Engineering, Marmara University, Turkey (corresponding author to provide phone: +90 (216) 77740 01; fax: +90 (216) 77740 01; e-mail: fserteller@marmara.edu.tr). economical according to digitally control more devices and processes, by reducing size and cost, as compared to a design using separate microprocessors, memories, and input/output devices [1]. Many control problems can be solved effectively by using microcontrollers [2], [3]. Because of this advantage, microcontrollers are widely used and developed rapidly in circuit designs in many areas such as day life devices, industrial control devices and metering -measurement devices [4], [5], [6]. That makes the widely used microcontrollers important for the education of students enrolled in electrical, electronic, computer, and mechatronics training programs [7], [8], [9], [10], [23].

Learning about microcontrollers is quite a complicated lesson for students. Traditionally, microcontroller courses have been taught by concentrating mainly on the architecture and programming of these devices, with very little spending effort to their practical applications [11], [12]. Thus, the most difficult task is to keep students engaged in that lesson, which will be the backbone of their careers. The aim should be to decrease the complicated lesson structure and to integrate theory with practice in their real lives [13], [14], [15], [16]. Students use simulation programs and experiment sets in training environments to facilitate learning the real-life applications of microcontrollers. Various microcontroller programming and simulation software programs are available for industrial and educational use. The software allows the user to develop and test all microcontroller-based designs before making a physical prototype [17], [18], [19]. If digital tools are fully exploited, they can offer innovation in teaching and ways to increase the attractiveness of learning [20]. Experiment sets are used to test the operation of the circuits that are created and tested with software packages in the real environment. Various microcontroller programming and electrical software programs are available for industrial and educational use [21], [22]. By using those sets of experiments, it is possible to carry out the work of many departments, from the simple applications to the complex applications, and the learning becomes permanent.

In the literature, there are various microcontroller experiments set. According to the study of Topaloğlu [24], he designed the experiment set with a $16 \mathrm{~F} 628$ microcontroller. It has realized the connection points that will obtain the highest efficiency from 16F628. The time spent on hardware design 
has been reduced to a minimum before developing programs on the card. Transitions between application modules on the card are provided with sockets used to join electronic materials.

Another study Özemirci et al. [10], They have developed Arduino Uno application set which is aimed to be easy to apply. It is a set that saves time with its hardware preparation in the work of the users and is portable and provides ease of transportation and storage. Thanks to the circuits on the application set, data detection, control and algorithm development applications can be made.

Another study Engin et al. [25], they designed a modular experiment set where each student performed his own microprocessor experiment set step by step depending on the course of the lesson. It has been observed that students' enjoyment items and success scores increased.

Another study Özcan et al. [26], Communication, Electronics, Control and Automation Technology Program students have been designed and implemented a $16 f 877$ experiment set so that students can perform the subjects they have learned in the microprocessors lessons. The developed experimental set was used by students in practice.

Another study İnce et al. [27], They designed an experiment set where they could develop pulse width modulation(PWM) signal generation, filter design, and digital analog conversion (DAC) applications with a microcontroller to teach students these subjects and practices.

Another study Kassem et al. [28], Created a training set for electrical and computer engineering students to develop microcontroller circuit designs. This set contains many applications on a single platform. Their aim is to prepare students for the actual world using the education set.

Asparuhova et al. [29], Performed the operation of temperature, humidity, flame and motion sensors controlled by the arduino uno microcontroller in the simulation program Proteus environment. They said that using the simulation program makes students flexible and creative.

Suryanarayana et al. [30], Microcontrollers called MicroLABlet programmable from USB have developed a training set. The microcontroller used in the training set is the 8051 microcontroller. The created training set was introduced and applied to the fourth term engineering students. It was seen that the students enjoyed creating prototypes and it was easier to understand the subject by the students.

In this study, the design of the $16 \mathrm{~F} 877$ microcontroller experiment set is realized. We have described and performed a novel learning environment design to comprehend the response of electric circuits. The modules in the experiment set are similar to those in the ISIS program. Because the modules are similar to the circuit diagrams of the simulations, students will not be strangers when practicing in the real environment. At the same time, the students will be able to reinforce what they have learned by using the experiment set outside the school.

\section{MATERIALS AND METHODS}

An important object of learning in engineering education is that students should understand and learn to use theories and models and link them to objects and events [13]. The new approach with the real-life equipment experiment set as methodological tools was prepared with that idea in mind. The designed experiment set consists of the main circuit platform, consisting of the 16F877 microcontroller and the modules on which experiments can be done. The single-sided copper plate used in the main circuit platform measures $200 \times 300 \mathrm{~mm}$ and the plate thickness is $1.60 \mathrm{~mm}$. In the circuit diagram of the project a 40 pin integrated socket is placed in the center of the copper plate where the $16 \mathrm{~F} 877$ microcontroller will be installed and a bus system is built around the microcontroller. The thickness of the data path created with pins around the microcontroller was set as $1 \mathrm{~mm}$. The energy paths thickness in the feed section is selected as $2 \mathrm{~mm}$. A total of 113 connection pads have been created on the main circuit board where the experimental modules can be installed. Signal and supply lines are combined with pads. Connection pads are drilled $4 \mathrm{~mm}$ wide. Female bullet banana plug Connectors are soldered to the copper part on the pads of the main circuit board. The paper containing the connection points, material drawings and naming is printed on the printer and adhered to the main circuit board. Figure 1 shows the 16F877 training kit and $3 \mathrm{D}$ printed circuit diagram. The microcontroller main circuit supply is provided by connecting the adapter to the +12 -volt power input connector and the main circuit supply is made active/passive with the ON/OFF switch. An in-circuit serial programming (ICSP) connection socket was created to load the microcontroller while experiments are carried out on the circuit. That means that it is not necessary to program the microcontroller from the circuit by cable and disconnect it each time, and it prevents the microcontroller's legs from being damaged.

The modules of the main circuit set were designed to be similar to the drawings in the ISIS program in order to make the microcontroller ready for operation. The basic connections of the microcontroller are modules of oscillator, +5-volt supply, and reset pin connections. Oscillators are used as a source for clock pulses used to process commands in microcontrollers. Since our microcontroller experiment set contains applications that require moderate power and frequency, the crystal oscillator (XT) circuit module is used oscillator. It is ideal to work with 5 Volts as supply voltage in the microcontroller. The pins 11 and 32 of the $16 \mathrm{~F} 877$ Microcontroller used are +5 Volts positive feed, and the pins 12 and 31 are GND negative feed. The +5 -volt supply module is designed with these ports in mind. Pin 4 is reset pin connection in $16 \mathrm{~F} 877$. If this pin is not connected over the +5 volt supply resistance the system operates unstable. To prevent this a reset pin connection module has been created. +5 -volt supply and reset pin connection modules, single sided copper plate is used and plate thickness is $1.60 \mathrm{~mm}$. Male bullet banana plug connectors are soldered to the copper part 


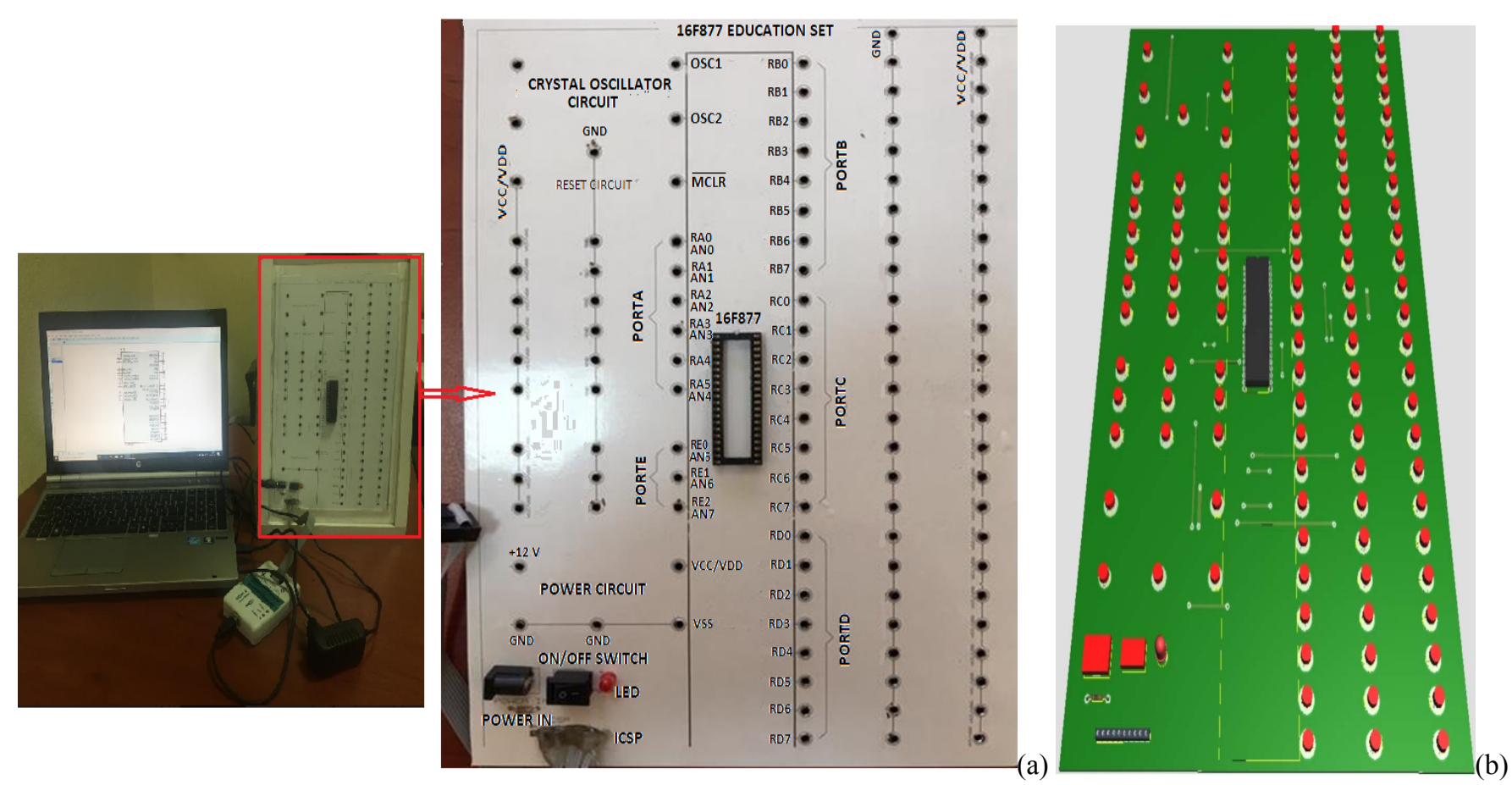

Fig. 3 Main circuit of the microcontroller training kit(a) and 3D printed circuit diagram (b).

on the pads of the modules. Paper containing connection points, material drawings and material name is printed on the printer and adhered to the respective modules. These new approaches, modules, ISIS drawings and 3D printed circuit diagram visualizations are introduced beginning with Figure
2. A drawing of the oscillator pin connection is shown in Figure 2(a), (b), (c), drawing of the +5-volt supply connectionis is shown in Figure 3(a), (b), (c) and the drawing of the reset pin is shown in Figure 4(a), (b), (c).
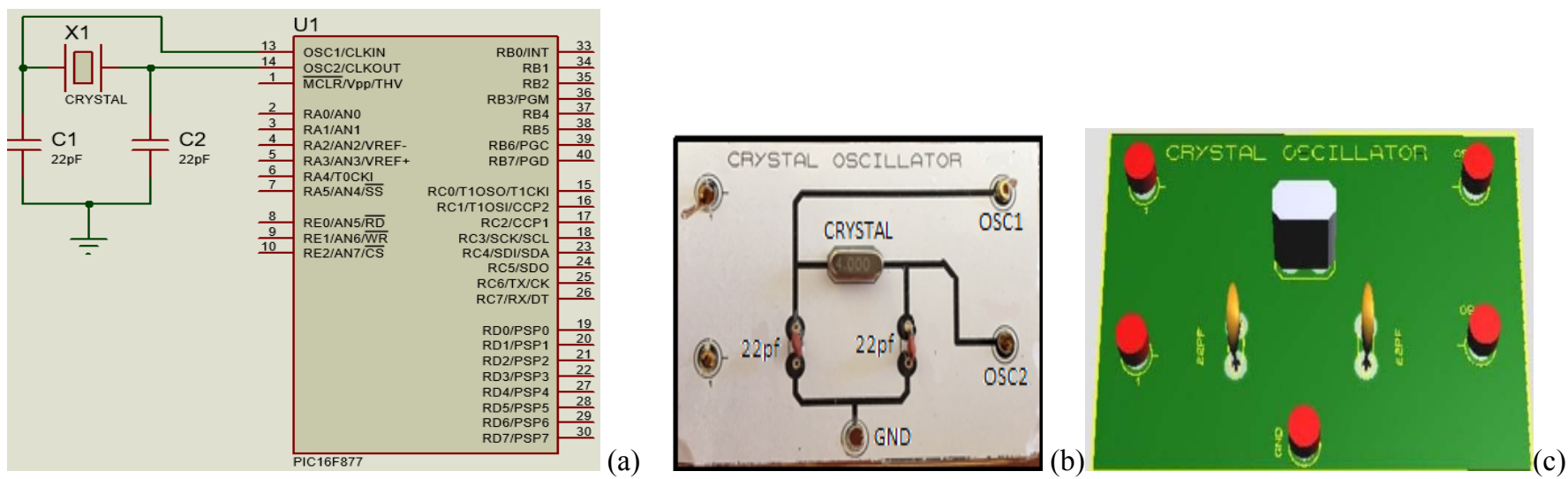

Fig. 2 Drawing of oscillator pin connection in ISIS program of microcontroller(a), training kit module design(b) and 3D printed circuit diagram(c).
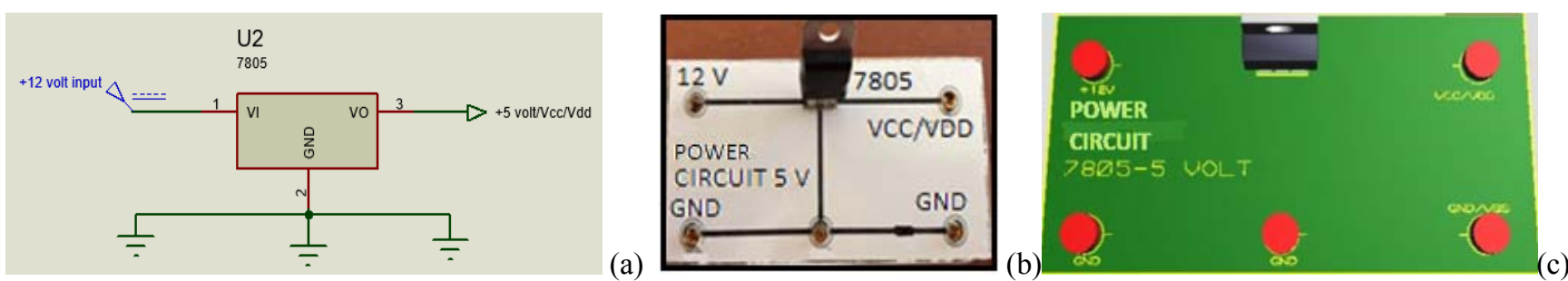

Fig. 3. Microcontroller in the ISIS program drawing the supply connection(a), training kit module design(b) and 3D printed circuit diagram(c). 


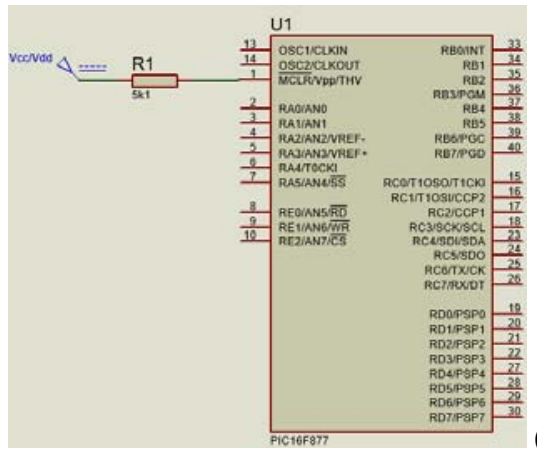

(a)
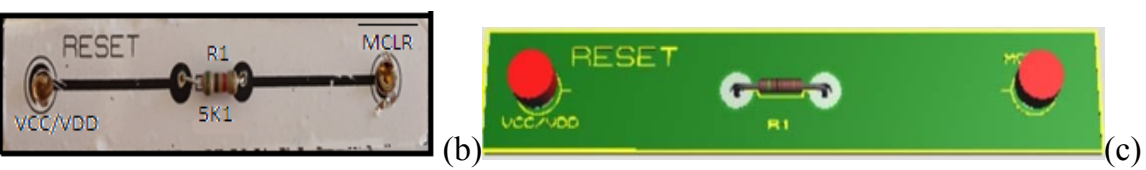

Fig. 4. Drawing of the reset pin connection in the ISIS program of the microcontroller(a), training kit module design(b) and $3 \mathrm{~d}$ printed circuit diagram (c).

After the basic connections have been learned, there are modules for students to learn and on which to practice basic input/output operations. Those modules consist of switches, LED, and LDR. The aim is to demonstrate elementary microcontroller applications using switches, LED and LDR indication. The modules are shown in Figures 5(a),(b),(c) 6(a),(b),(c) and 7(a),(b),(c), respectively. The button, LED, and LDR modules are plugged into the pins of the ports
PORTB, PORTC, and PORTD of the experiment set. Students can perform and experience learning activities visually by using the modules and attaching the modules to the specified ports. Because the modules are implemented as real components, working with a team and developing the idea on modules is more suitable then other classical simulation programs.
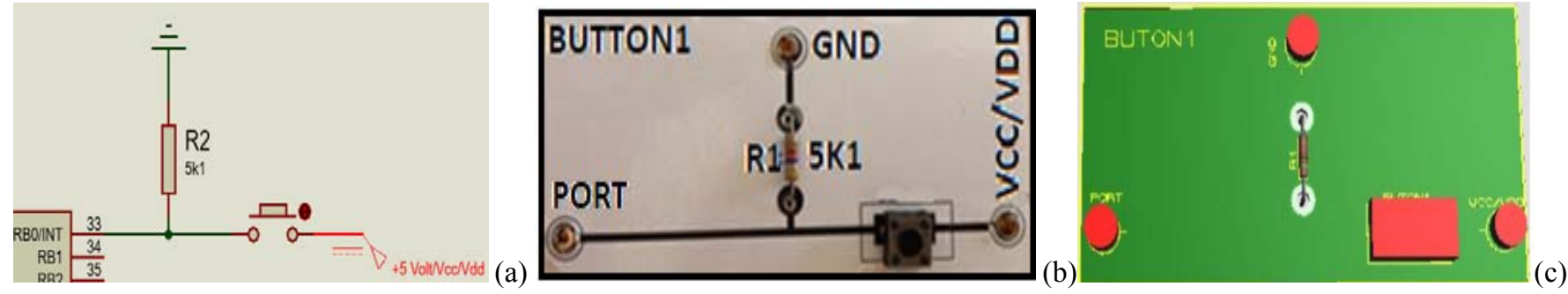

Figure 5. Drawing of switch connection circuit in ISIS program(a), training kit module design(b) and 3D printed circuit diagram(c).

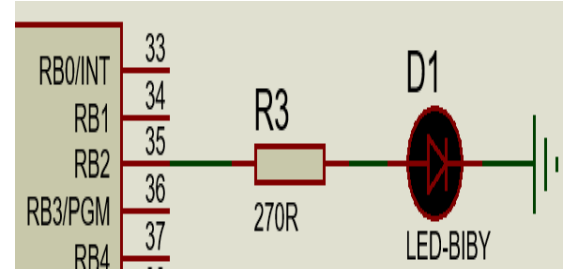

(a)
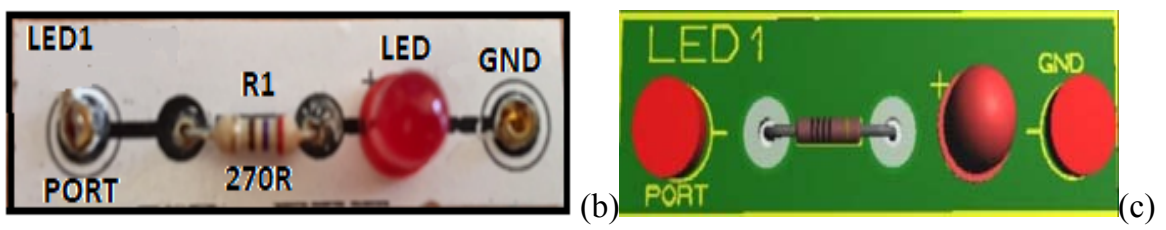

Figure 6. Drawing of led connection circuit in ISIS program(a), training kit module design(b) and 3D printed circuit diagram(c).

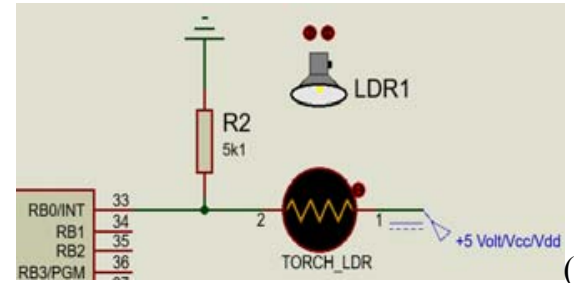

(a)
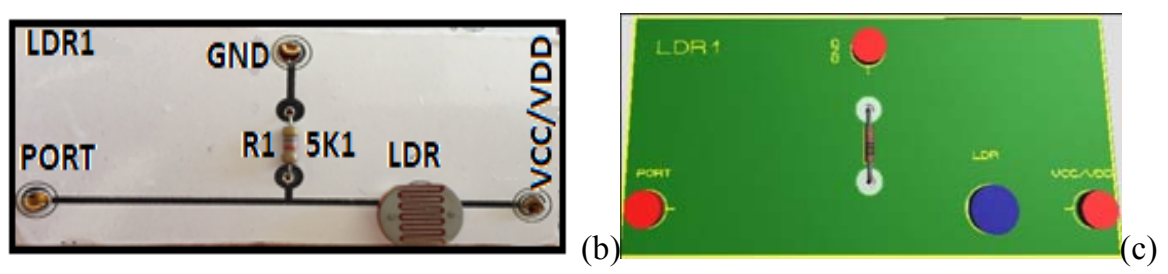

Figure 7. Drawing of LDR connection circuit in ISIS program(a), training kit module design(b) and 3D printed circuit diagram(c). 
It is necessary to start with the easiest-to-learn universal 8bit controllers, since the study of more complex 16- and 32-bit series microcontrollers [19]. Experimental modes have been designed in which students can realize a seven-segment display, 2 lines 16 characters Liquid Crystal Display (LCD) (8-bit and 4-bit) displays and a stepper motor application. One common anode indicator was used in the design of the 7 segment display module. In the indicator used, 8 data pins and 2 GND pins are used. The logic 1 signal is applied to the data pin to which the segment that is desired to give light is applied and the LED is illuminated. In the LCD display design, 2 lines 16 characters LCD are used. The LCD has a total of 14 pins. The connection of the used LCD to the microcontroller can be made in two ways, 4 bits and 8 bits. The advantage of the 8 bit connection is that the data to be written on the screen is sent faster but this is not very clear from the eye. The advantage in 4-bit connection is that 4 pins are used less in the microcontroller and extra hardware can be connected to these pins. A 5-pin unipolar stepper motor is used in the design of stepper motor module. The common end of the stepper motor is connected to ground and the other 4 ends are connected to the +5 volt supply via transistors. The control of the transistors is provided by the signals sent over the microcontroller pins. Those modules are shown in Figures 8(a) and (b), 9(a) and (b), 10(a) and (b), and 11(a) and (b), respectively.
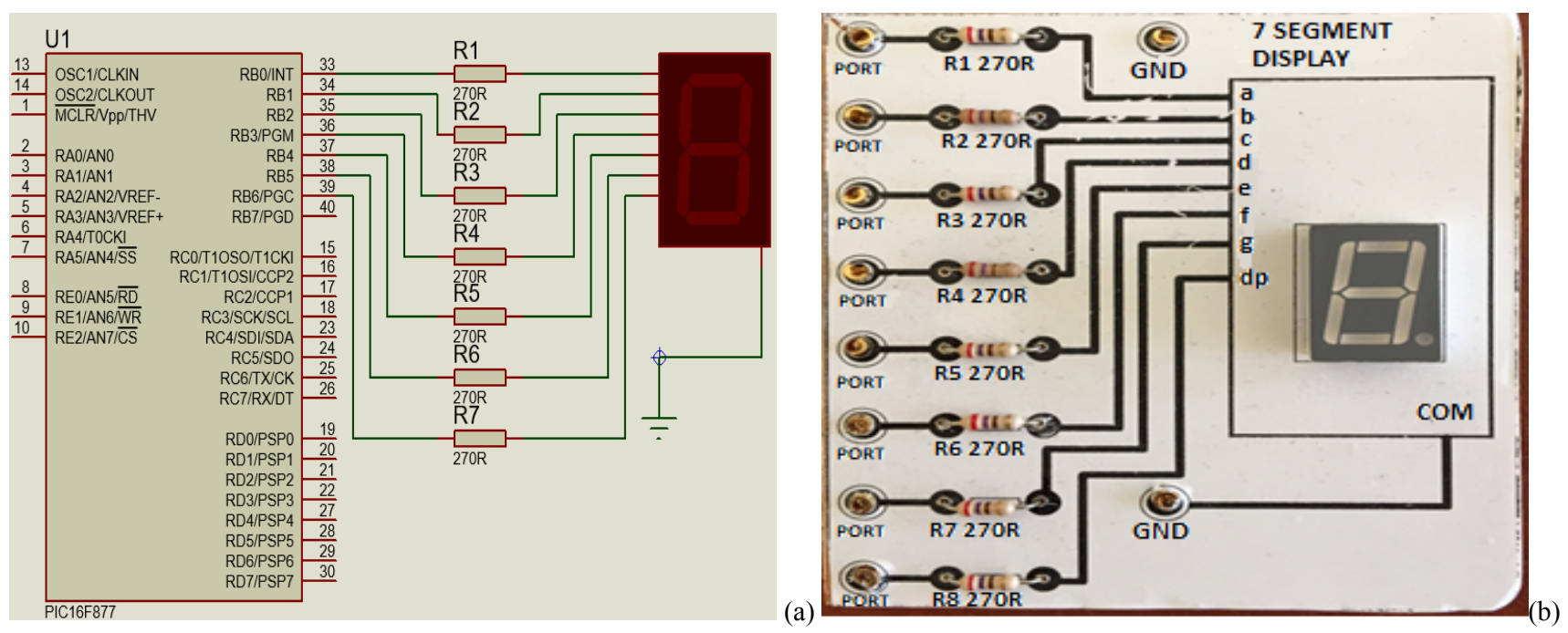

Fig. 8. Drawing of seven segment display connection circuit in ISIS program (a) and training kit module design (b)
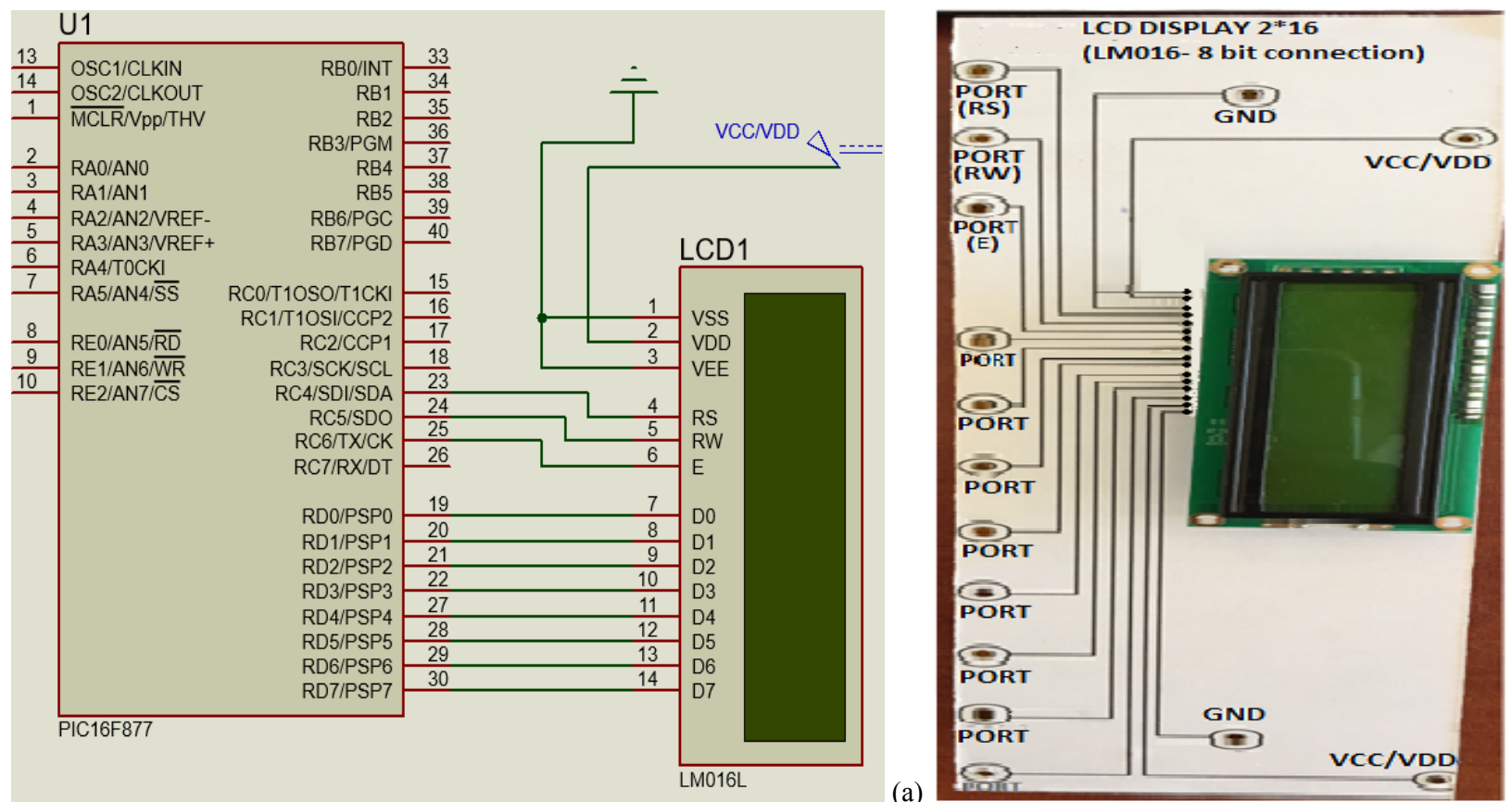

Fig. 9 Drawing of LCD display (8 bit) connection circuit in ISIS program(a) and training kit module design(b). 

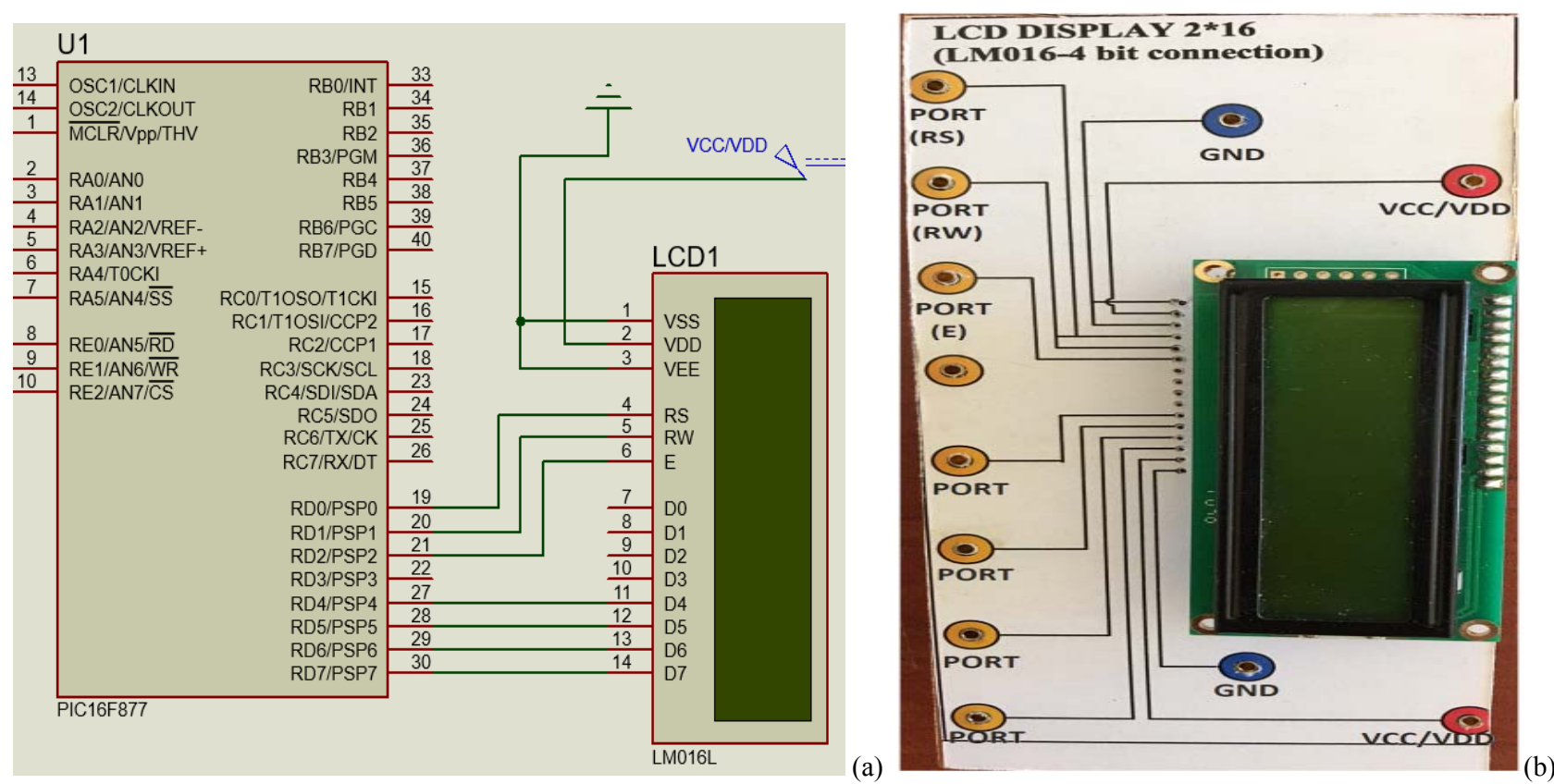

Fig. 10 Drawing of LCD display (4 bit) connection circuit in ISIS program(a) and training kit module design(b).
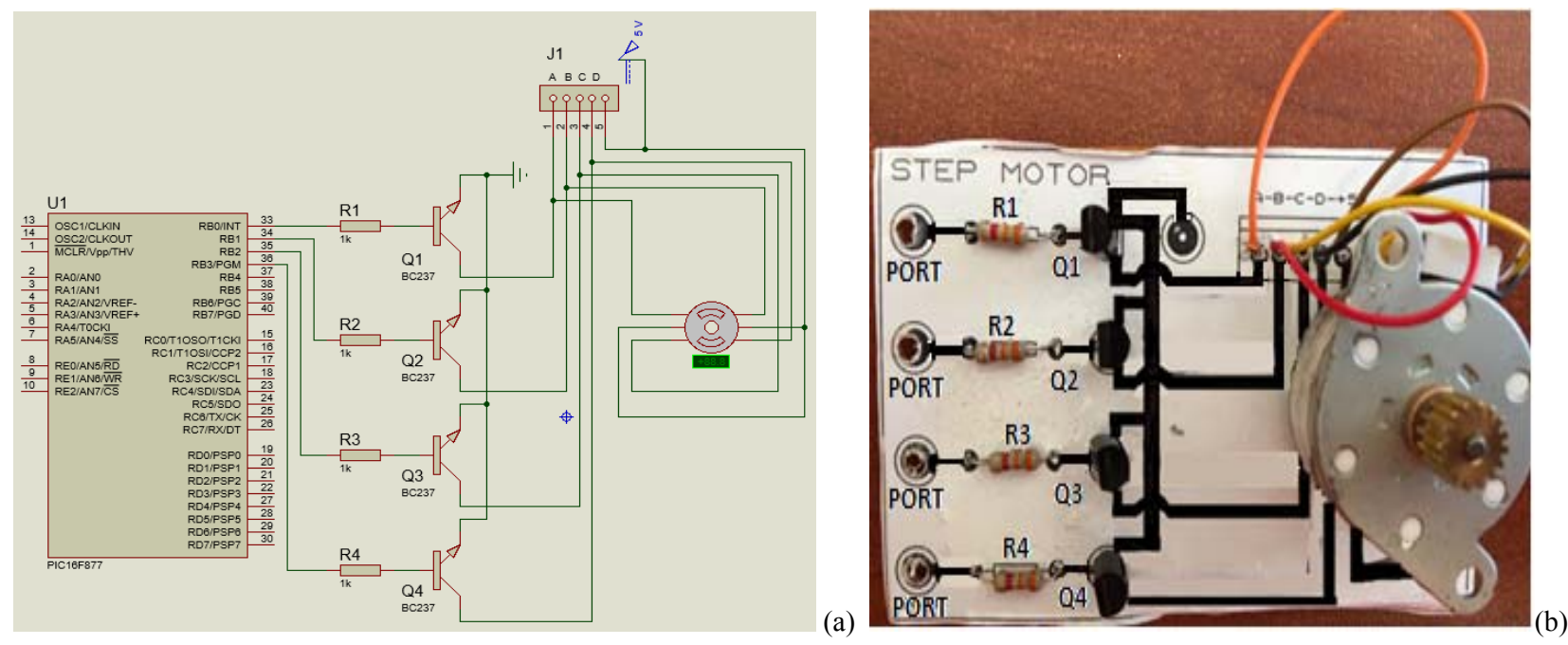

Fig. 11. Drawing of stepper motor connection circuit in ISIS program(a) and training kit module design(b).

\section{DISCUSSION AND FINDINGS}

This study tried to simplify by matching the microcontroller equipment schematic displaying to real- life equipment. Thanks to these modules and additional modules, the students are able to practice what they have been taught without cooling off from the educational environment, because there is no disconnect between the simulations and real connections. A large sample area can be created through the study, and it contributes to the learning of the students.

With the designed system, the students can realize all the applications in the following areas:

- LED on-and-off applications with buttons

- LED lamp light brightness intensity control applications
- Seven-segment display and LCD control applications

- Analog/digital conversion applications with potentiometer

- Motor speed control application with potentiometer

- Stepper motor control applications

- Servo motor control applications

With the implementation of training kits, the teaching methodology takes a shift from the classical method to a new paradigm. With this new design set, the student gets the hands-on experience of converting theorical information to a real-life experiment.

Microcontrollers course was created to examine the use of the designed microcontrollers training set and its contribution to learning. midterm and final exams were conducted to determine the learning levels of the participants. The research 
covers the 2019 and 2020 periods, respectively. The course was held with the participation of consisting of Biomedical Device and Mechatronics Technology Program students. In total, 72 participants used only ISIS program circuit drawings in 2019 period and 65 participants used ISIS program circuit drawings with microcontrollers training set in 2020 period. Among the participants, those who were in daytime education were named as 1 st education and those who were in evening education were named as 2 nd education. For this purpose, the exam grades and comparison of the three student groups participating in the microcontroller course are shown in Table 1.

Table 1. Average of midterm and final exam scores of the participants in the microcontroller course in 2019 and 2020 period and comparison.

\begin{tabular}{|c|c|c|c|c|c|c|c|}
\hline \multicolumn{5}{|c|}{2019 Period } & \multicolumn{2}{|l|}{2020 Period } & \multirow[b]{2}{*}{ Difference } \\
\hline $\begin{array}{l}\text { Program } \\
\text { Name }\end{array}$ & Exam Name & $\begin{array}{l}\text { Participants } \\
\text { Number }\end{array}$ & $\begin{array}{c}\text { Class } \\
\text { average }\end{array}$ & Exam Name & $\begin{array}{l}\text { Participants } \\
\text { Number }\end{array}$ & $\begin{array}{c}\text { Class } \\
\text { average }\end{array}$ & \\
\hline Bio. techy. & Midterm & 30 & 48,83 & Midterm & 35 & 68,57 & $+40 \%$ \\
\hline 1st edu. & Final & 35 & 56,34 & Final & 33 & 58,64 & $+04 \%$ \\
\hline Bio. techy. & Midterm & 25 & 38,54 & Midterm & 30 & 56,67 & $+47 \%$ \\
\hline 2nd edu. & Final & 23 & 65,65 & Final & 28 & 53,75 & $-19 \%$ \\
\hline Mechat.techy. & Midterm & 13 & 38,08 & Midterm & 27 & 59,44 & $+56 \%$ \\
\hline 1st edu. & Final & 14 & 44 & Final & 26 & 48,81 & $+10 \%$ \\
\hline
\end{tabular}

According to Table 1, it is seen that the scores generally increase when looking at both the midterm and final averages of the classes, and at the differences. In particular, the success of the mechatronics students is obvious, increasing by $56 \%$ and $10 \%$ for the midterm and final exams, respectively. The reason for the success of the students in the mechatronics technology program is higher because the majority of the students of the mechatronics technology come from the fields of electrical electronics and mechatronics in vocational high schools, because they have a better knowledge of basic electrical electronics and some of them have little prior knowledge about microcontrollers. Participants, who have experienced the real-life equipment module, have responded to say that they have learned a great deal about microcontrollers and have collected the relevant information from their applications to solve real engineering problem. As the microcontrollers experiment set is simple and modular, the students stated that their concerns such as using the wrong circuit element, damaging the experiment set and not being able to recognize the circuit elements are eliminated and it is also enjoyable to practice on the experiment set.

\section{A. Limitations}

This study is limited with some factors. First, it limited with two consecutive periods. To have the more information about participants' scores, the periods numbers can be increased. Second, the participants also joined the course only from three program; the program number should be increased and be diversified especially technical branch taking account. Additionally, the study was confined to microcontroller reallife equipment.

\section{B. Future work}

This study will be diversified by designing experiment modules of various machine controls, temperature sensor applications, humidity sensor applications and serial communication applications. Since the importance of distance education has increased greatly as a result of the pandemic, elaboratory applications should be adopted and developed for effective use in the courses with the applications. With the elaboratory, in schools providing formal education, the opportunity to perform experiments that cannot be done during the lesson will also be provided. Also e-laboratory applications will enable and encourage the students to practice and consolidate their knowledge with ease. In that context, our next target will be to transform our microcontroller training set into e-laboratory application training by increasing the number of experiment modules. So, the students, will be able to perform their laboratory applications from any environment with internet by using their personal computers without coming to the laboratory environment.

\section{CONCLUSION}

Although microcontroller-training kits currently are used in various simulation programs and experiment sets, the problem is that the microcontroller experiment sets are not similar to the circuit diagrams that are used by the students in the simulation programs. In this study, microcontroller training sets and modules were designed with a new approach to teach the microcontroller lessons better in engineering-based departments. To make the learning activities more permanent, basic microprocessor training modules compatible with the visuals of the circuit drawings in the ISIS simulation program used in microcontroller training were provided in the designed training set. Because the application set does not require wiring, students do not waste time on circuit installation in their experimental studies. In addition, malfunctions due to incorrect cable connections are prevented. After the users draw the circuits they create in the ISIS simulation program, they can easily create their circuits by attaching the respective modules in the experiment set to the connection points on the main circuit board. The complicated circuit connections have been removed from the center of the set, resulting in a simpler training set. Because the design of the training set is simple, 
students can easily create the training sets themselves, so they gain the skills needed to create printed circuit boards, recognize electronic components, and solder electronic components into the circuits. The modules in the education set can be diversified, allowing students to develop high-level knowledge in their work on microcontrollers. The experiment set allows students to develop more applications in a shorter time. This new development approach will be a resource for those who want to develop a microcontroller training set.

\section{References}

[1] M. R. Tarafder, M. L. Ali, "Development of a computer aided learning tool for pic microcontroller", International Conference on Industrial Engineering and Operations Management (IEOM 2016), 8-10 March 2016.

[2] C. F. Yeong, H. A. Rahman, E. S. Ming, "A Hands-on approach to teaching microcontroller", Journal of Systemic, Cybernetics and Informatics, Volume 11(1), pp.55-59, 2013.

[3] G. Mostafa, "Development of an 8-bit RISC microcontroller learning kit using atmel ATmega32 architecture", 2nd International Conference on Advances in Electrical Engineering (ICAEE), Dhaka, 2013, pp. 154159.

[4] E. Montanez, "Micro-controller in education embedded control- everywhere and everday", American Society for Engineering Education Annual Conference \& Exposition (ASEE 2015), 12-15 June, Portland-Oregon, 2005.

[5] B. Su, L. Wang, "Application of Proteus virtual system modelling (VSM) in teaching of microcontroller", 2010 International Conference on E-Health Networking Digital Ecosystems and Technologies (EDT 2010), Volume 2, 2010, pp. 375-378.

[6] Y. Bektas, N. F. O. Serteller, "Brushless direct current (BLDC) motor driving experimental set", Energy education science and technology part a-energy science and research Vol. 27(2), pp. 455-466,2011.

[7] C. Ma, Q. Li, Z. Liu, Y. Jin, "Low cost AVR microcontroller development kit for undergraduate laboratory and take-home pedagogies", 2010 2nd International Conference on Education Technology and Computer (ICETC 2010), Volume 1, V1 35-V1 38.

[8] F. Y. Limpraptono, H. Sudibyo, A. A. P. Ratna, A. S. Arifin, "The design of embedded web server for remote laboratories microcontroller system experiment", In TENCON 2011-2011 IEEE Region 10 Conference, 2124 Nov, 2011 Bali-Indonesia ,1198-1202.

[9] H. Çimen, M. Nartkaya, I. Yabanova, S.M. Çinar, "A new microcontroller experiment set for undergraduate students", 4th International Forum on Engineering Education-Integrating Teaching\& Research with Community Service, 2006.

[10]E. Ozdemirci , C. Ersin, , M. Canal, "Arduino uno uygulama setinin gerçekleştirilmesi”. Mehmet Akif Ersoy Üniversitesi Fen Bilimleri Enstitüsü Dergisi , 8 (Özel (Special) 1), pp. 127-133. 2017.
[11]A. Hanson, "A microcontroller laboratory for electrical engineering seniors", IEEE Trans. Educ. E24, pp. 8-14. 1981.

[12] T. N. Mayer, M. E. L. Jackson, "A new role for microcontroller courses: integrating EE curricula". Frontiers in Education, 25th Annual Conference, November 1-4, Georgia Institute of Technology, 1995.

[13] A. K. Carstensen, J. Bernhard, "Student learning in an electric circuit theory course: Critical aspects and task design", European Journal of Engineering Education, in vol. 34, issue 4, pp. 389-404,August 2009.

[14] S. Nethravathi, R. S. Geetha, "Learning by doing: implementing in microcontroller course",Journal of Engineering Education Transformations", Special Issue, 2016.

[15]H. Apaydin, N. F. Serteller, "Design and control application of stepping motor for ventilating system", IEEE IEMDC 2007, Proceedings of the international electric machines and drives conference, Vol 1 and 2, pp. 1590-1593, 2007.

[16] S. Aslam, M. Ahsan, S. Hannan, M. Hamza and M. Jaffery, "Development of a software based PIC24F series microcontroller educational trainer", 2019 International Conference on Engineering and Emerging Technologies (ICEET), Lahore, Pakistan, 2019, pp. 1-5.

[17] S. S. Kendre, P. V. Mulmule, S. D. Shirbahadurkar, "Developing experimental platforms using common software tools for enhancing technical skills of electronics engineering students in microcontrollers", 2013 IEEE Frontiers in Education Conference (FIE 2013), USA.

[18]A. B. Koc, C. Koc, M. Vatandas, "Software tools for teaching microcontroller programming in agricultural engineering education", American Society of Agricultural and Biological Engineers. In 2008 Providence, 29 June-2 July, 2008.

[19] V. K. Abdrakhmanov, N. N. Bikbaev, R. B. Salikhov, "Development of low-cost electronic training boards based on universal microcontroller", 13th International Scientific-Technical Conference APEIE, 2016

[20] L. M. Gorghiu, G. Gorghiu, "Related aspects on using digital tools in the process of introducing nanotechnology in science lessons", Acta Physica Polonica A,125.2 ,2014, pp.544-547.

[21] S. Bakircilar, A. T. Ozcerit, "Programlanabilir CPLD tabanlı akıllı mikrodenetleyici eğitim seti tasarımı ve uygulamas1, (Micrcontroller experiment set with CPLD)", Sakarya Üniversitesi Fen Bilimleri Enstitüsü Dergisi, 19(2),2015, pp. 123-133.

[22] V. Rankovska, "A case-study approach in microcontroller education", Conference: IX International Scientific Conference on Information, Communication and Energy Systems and Technologies, Serbia, june 25-27, 2014.

[23] M. Işı1k, M. Yağc1, "Realise and design of application development kit for pic", 2nd International Congress on the World of Technology and Advanced Materials (WITAM-2016), 28 September-02 October, 2016, Kırşehir/Turkey. 
[24]N. Topaloğlu, "Prototip bir PIC programlama ve deney setinin tasarımı", 6th International Advanced Technologies Symposium (IATS'11), 16-18 May, 2011, Elazığ, Turkey.

[25]M. Engin, D. Engin, "Mikroişlemciler dersi laboratuari için yeni deney seti tasarimi”, C B Ü Soma Meslek Yüksekokulu Teknik Bilimler Dergisi, Cilt: 2 Sayı: 8, 2007

[26] M. Özcan, H. Günay, "Mikrodenetleyici geliştirme seti tasarım ve uygulamaları", Journal of Selcuk-Technic, vol. 8/3, 2009, pp. 307-320.

[27] S. İnceli, M. Yuksekkaya, "A digital to analog voltage converter experiment for microcontroller course", The Eurasia Proceedings of Educational and Social Sciences 6, 2017, pp.114-120

[28] A. Kassem, M. Hamad, C. Bechara, M. Khattar, "An educational board for teaching microcontroller system design laboratory", International Journal of Computing \& Information Sciences, 12(1),2016, pp.1-9.

[29]K. Asparuhova, D. Shehova, S. Lyubomirov, "Using Proteus to support engineering student learning: microcontroller-driven sensors case study", 2018 IEEE XXVII International Scientific Conference Electronics ET, Sozopol, 2018, pp. 1-4.

[30] K. Suryanarayana, H. S. Hatwar, M. R. Rao, "Design and development of 8051 microcontroller kit micro-lablet for active learning”, 2017 5th IEEE International Conference on MOOCs, Innovation and Technology in Education (MITE), Bangalore, 2017, pp. 146-151.,

H. Apaydin was born in Demirci, Manisa. He is graduated in 2003 from Marmara University, and master's degree in 2006 at Marmara University of Science and Technology institute, Turkey, and he continues his doctorate education at the same university since 2019 . He is currently working as a Lecturer in the Department of Biomedical Device, Technology Program at Kütahya, Dumlupınar University, Turkey from September 2009 onwards. His research interest involves in electronic circuit design, engineering education, control systems and special electrical machines.

N. Fusun Oyman Serteller, in 1998 graduated from the Istanbul Technical University -ITU (Faculty of ElectricElectronic Engineering). In 1996, completed postgraduate studies at ITU and in 2000, completed doctorate at Marmara University Technology Faculty Electric-Electronic Engineering. Assistant at Marmara University, lecturer at Marmara University of Electric-Electronic department. In 2000, assistant professor at University of the Marmara and since then working as professor. Research areas are control of electric machine, electric machine design, numeric analysis of electrical system, electromagnetic field theories, engineering education. 